\section{IN BRIEF}

- Although the Internet is not a 'killer application' for dentistry, it does have many excellent uses.

- Linking the Internet with dental system software can increase the scope and efficiency of practice management.

- Communicating with patients and other members of the dental profession using the Internet can be extremely valuable.

- Utilising dental and business software from the Internet can be of great benefit.

- E-learning, in all of its many guises, will become increasingly important.

- To fully utilise the Internet at work, practices need to ensure that all of their team members have the appropriate hands-on training.

\title{
Putting it all together; dentistry and the Internet
}

\author{
P. K. Downes ${ }^{1}$
}

This last chapter in the series looks at how the Internet, 'warts and all', can be used in the practice setting. The web in particular has changed dramatically in the last three or four years, and the phrase 'Web 2.0' was coined to reflect this perceived change in the way that the web was being used. Web-based communities, social networking, the transition of websites from mere information pages to real software applications and the expansion in broadband access have all been important factors in this 'improved' WWW. Has dentistry been able to keep up with this pace of change and are dentists willing to embrace what the Internet has to offer?

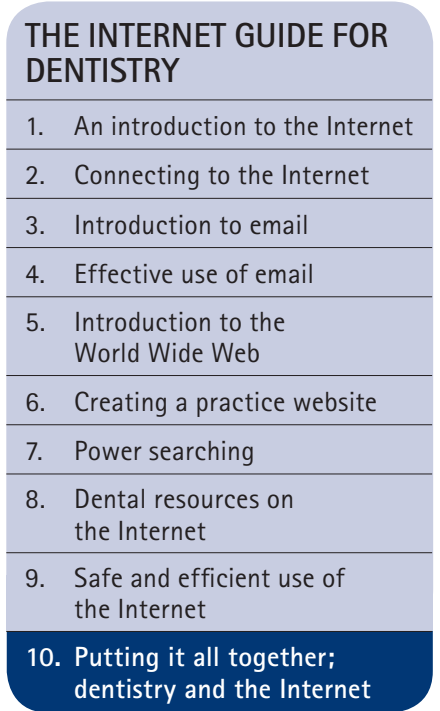

${ }^{1}$ General Dental Practitioner, Kelvin House Dental Practice, 2 Nelson Road, Whitstable, Kent, CT5 1DP

Correspondence to: Dr Paul K. Downes Email:paul@pdownes.fsnet.co.uk

\section{Refereed Paper}

$\odot$ British Dental Journal 2007;

203: 75-86

DOI: $10.1038 / \mathrm{bdj} .2007 .633$
Schleyer et al., in their paper The technologically well-equipped dental office ${ }^{1}$ gave a state-of-the-art view on how to integrate IT applications in dental practice. The vast majority of UK dental practices are a long way from their vision of dental IT 'utopia'. In correspondence with the Dental Practice Division of the Business Services Authority, (June 2007), they confirmed that approximately $25 \%$ of documents (claims) currently received from dentists are still paper based. Not all UK dental practices run dental system software, or have access to the Internet; fewer still have learnt the necessary IT skills to make full use of the Internet.

So how is the Internet actually being used in UK dentistry today? To help to explore this area I will look at how dentists are currently benefiting from the advantages that the Internet can bring. I will also draw attention to some of the downsides of using the Internet.

\section{A) LINKING THE INTERNET WITH DENTAL SYSTEM SOFTWARE}

Many dental electronic patient records systems have developed strategies for implementing Internet technology within their dental system software. It is possible to send an automatic email reminder to patients about their forthcoming appointment, per- form email marketing, send and receive email attachments, make appointments for existing and new patients via a practice website, obtain email support from the supplier and receive live online training for staff. The dental system software can automatically keep a record of all emails sent/received and these are linked to each patient's record. Some system software uses pure text for email (no html formatting) and, as an additional safety measure, attachments have to be manually saved before they can be opened. The cost of sending hundreds of emails is negligible, both in terms of money and staff time. Online booking reduces the workload for the receptionist, while e-marketing can be a costeffective way of augmenting more traditional marketing methods. Some of the dental system software companies now offer an online, encrypted backup and recovery service for the patient/practice management database files. From these examples, it can be seen how having the dental system linked to the Internet can increase the efficiency and scope of practice management.

Most electronic communication with the NHS Business Service Authority (BSA; formerly the Dental Practice Board) has been via electronic data interchange (EDI), with Global Crossing providing a private network for 
Fig. 1 The ability to send digital images as email attachments has greatly enabled the process of twoway communication between members of the dental team. Close-up images of the adjacent teeth can be of great assistance to the dental technician when adding characterisation to a crown or bridge

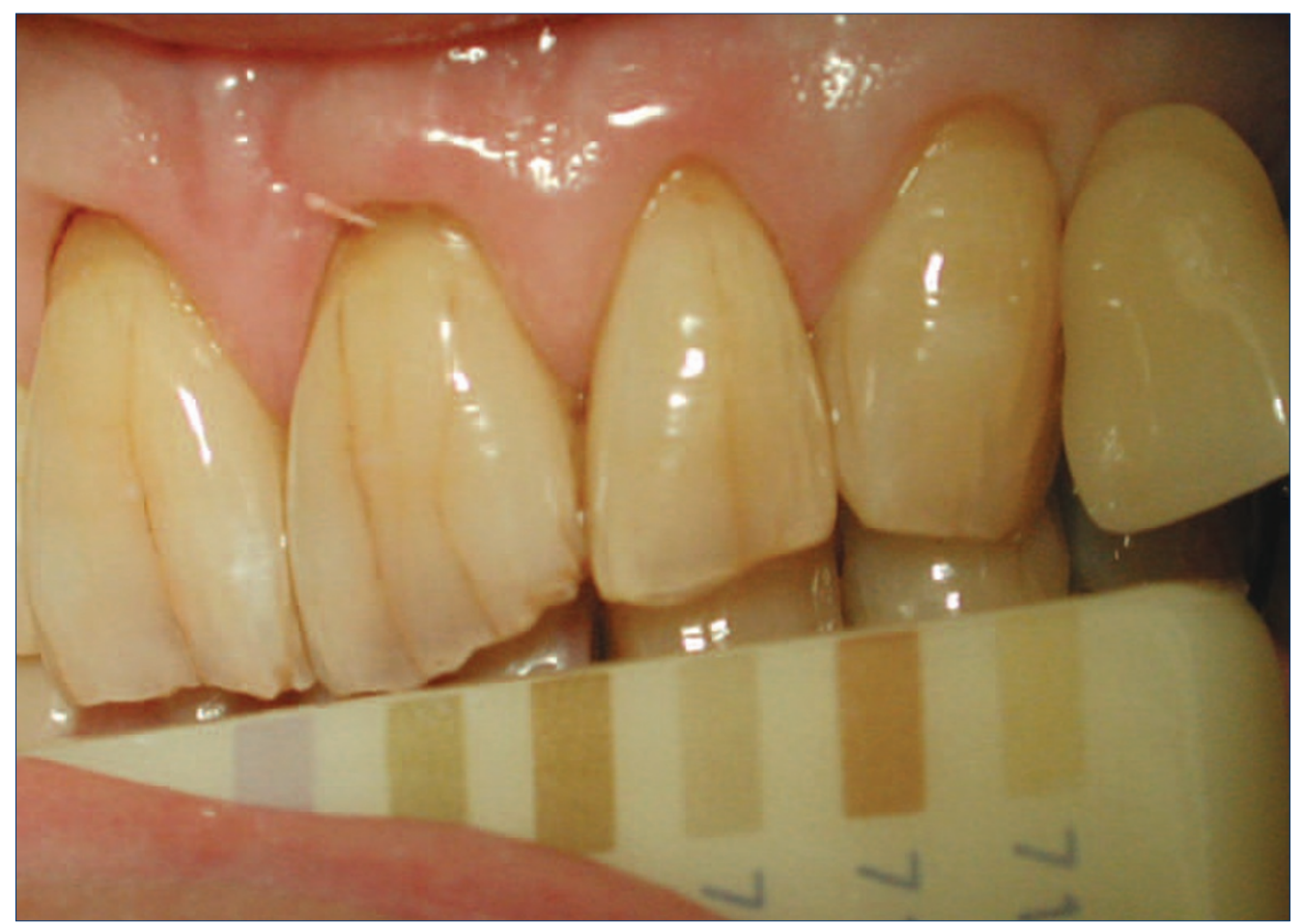

dental practices to link with the BSA. This obsolete method will discontinue in August 2008 and will be replaced by their WebEDI service; this is an encrypted Internet-based submission service. The BSA has been developing a number of other Internet initiatives that rely on all dental systems being able to output data in a common format and include:

- A transferable electronic patient record

- Enabling NHS numbers in dentistry (END) service. The NHS number is becoming the unique patient identifier used across the NHS, and could automatically be added to clinical records held by GDPs.

With the wide adoption of broadband in the UK, Microsoft are now looking at implementing Software as a Service (SaaS) for small UK businesses and this may include dentists. SaaS is web-based delivery of software where users are able to access and manage commercially available software online. The software company provides maintenance, daily technical operation and support for the software provided to the user.

A word of caution: any dental practice that links their current dental system to the Internet has to be aware of potential security risks, as outlined in the previous chapter. The patient database is crucial to the running of a dental practice and expert help should be sought to ensure that this information is not put at risk. Staff should have the appropriate training and there should be a practice policy on the use of email and the web in the workplace.

\section{B) COMMUNICATING USING THE INTERNET Undergraduate intranets}

Most dental schools now have an intranet for dental students, accessible from any computer on the Internet by means of a username and password. This normally contains timetables, lecture notes, electronic courses, handouts, a year list, past papers, news blog and contacts.

\section{Email}

As well as using email to communicate with patients, email can also be used to communicate with a wide number of other parties, such as dental organisations, dental trade companies, specialist referral services and primary care trusts.

\section{Email attachments}

Dentistry is a very visual profession and the use of digital imaging has really enhanced the process of two-way communication. Sending digital images to laboratories as email attachments is now commonplace (for example, see the digital gallery at Filippini and Gray's dental laboratory website ${ }^{2}$ ). The use of such photographs can greatly facilitate the communication of shade, characterisation, occlusion and soft tissue morphology (see Fig. 1).

For specialist referrals it is of course possible to include images of study models and digital X-rays (or digital copies of traditional $\mathrm{X}$-rays created using a digital camera and a light viewing box). When sending clinical images it is important to consider patient confidentiality and it is good practice to use the minimum amount of patient identifiable information necessary. Electronic referrals are set to become an important part of the new NHS National Strategic Plan.

\section{Podcasts}

The Dental Practitioners' Association (DPA) has developed a series of free podcasts available from their website ${ }^{3}$ for members and 
non-members. A podcast is a digital recording of a radio broadcast or similar programme, made available on the Internet for downloading to a personal audio player, in this case, Apple's iTunes. The DPA is using podcasts to communicate the latest news and present interviews and information about a range of issues affecting dentistry in the UK.

\section{Practice website and CD-ROM}

More and more practices are using their practice website to proactively communicate with their patients. Dental practice websites often include a current fee guide, recent newsletters (using the pdf format for a professional look), a dental shop for selling dental care products, a new patients welcome pack for downloading/printing, patient education leaflets/animations, an interactive 'walk through' of the practice building and recent news stories on dentistry. It is also possible to produce a CDROM (either full size or business card size) version of the practice website to hand out to new patients. Hyperlinks from the CD-ROM will work seamlessly on any Internet-enabled computer. A CD-ROM could also contain additional multimedia content that may be too large to put on the website or could even be customised to include pre-treatment digital images of the patient's dentition.

\section{Patients wanting to research healthcare}

Patients are increasingly using the Internet to find out information about dental/medical conditions and their various treatment options. ${ }^{4}$ Dentists should be aware that patients are using the Internet for healthcare research and should be in a position to recommend suitable sites for them to consult (see section on dental resources). There are also dental selfhelp sites such as Archwired, ${ }^{5}$ a blogger site (a diary of personal thoughts) for teenagers and adults who are having orthodontic treatment. Even if you never carry out orthodontic treatment, this site offers a fascinating insight into what patients really think about their dental treatment and their dentists.

\section{Online ordering}

Ordering dental equipment and materials via a modem has been available for many years, and more recently companies such as the Dental Directory ${ }^{6}$ and Schottlander ${ }^{7}$ have extended this service to include online ordering. Some companies offer an additional discount for ordering goods online. The Internet also opens up a whole global marketplace for dental products. For example, dental speakers from abroad sometimes recommend products that are only available in their own country; with the Internet it is now much easier to track down such products.

Although not yet available in the UK, there is a dental supply price comparison site in the US called Net $32^{8}$ that brings together dental products from 60 different supply sources.
From this website it is possible to buy items from multiple vendors at the lowest price by placing just one order.

Collaboration projects - merging books with electronic media

A very interesting online collaboration has been taking place with the idea of merging a book with the web. Computing in dentistry ${ }^{9}$ is a new book about computer technology in dental practice and is being written by leading experts from the Center of Dental Informatics, Pittsburgh, USA. The work has been in progress for a number of years with chapter outlines and various finished sections being available online for future readers to give comments and feedback. This collaboration between the authors and readers will continue after the printed book is published since there will be a community section that will enable people to talk to other readers of the book, share experiences, and learn from others. Authors will staff this community and will be able to provide authoritative replies and advice. The website will complement the printed version and extend its usefulness and functionality. Updated content, full search functions, online tests, direct access to other Internet resources and web links that are constantly maintained are among the benefits of the website. Meanwhile, some conventional books, such as Contemporary orthodontics edition ${ }^{10}$ ( $4^{\text {th }}$ edition), allow readers to access the book online, retrieve new information since the book was printed and download images from the book for use in lectures.

\section{Communication between the dental team}

Perhaps the most useful element of Internet communication, but one that is often overlooked, is the direct communication amongst the dental team. There are many web and email forums available to dentists and some of these are listed in section 8. You may ridicule the statement on the Dentaltown ${ }^{11}$ website ('With Dentaltown... no dentist will ever have to practice solo again ${ }^{S M}$ ') but with over 60,000 members it has obviously struck a chord with many dentists (there is also a Hygienetown website for hygienists).

If you prefer a UK bias then you cannot beat the free GDP-UK ${ }^{12}$ mailing list for homegrown dental discussion; it is available in both email and web format and currently has over 1,800 members. Here is a recent quote from Tony Jacobs, a GDP from Manchester, who is the founder of the mailing list: 'The GDPUK mailing list has brought together a whole group of people who only know each other by name and their email addresses. The list provides a place for them all to collaborate and is often the place where breaking news about dental topics get their first airing.'

There has been a considerable increase in the number of subscribers and messages to the GDP-UK mailing list during the last couple of 
years, almost certainly caused by the scarcity of information about the 'new' NHS contract (nGDS). In any one month, approximately $10 \%$ of the membership writes a message; this may seem like only a small percentage but it is actually quite a high figure for online forums. A high proportion of members are quite happy just to read the messages; they have the affectionate title of 'lurkers'! The Internet has been cited $^{13}$ as being successfully used by dentists to organise a protest group about the nGDS contract. This shows that the Internet can be a unique avenue of communication for dentists who wish to be able to talk to other dentists about issues of mutual concern and interest.

The success of sites such as GDP-UK also serves to highlight one of the potential problems with communicating via the Internet. New communication technologies have not displaced older technologies; they have just added more layers over existing systems. We can now communicate by email and web forums, but we still have letters, magazines, telephone and fax to deal with. This increase in the number of ways we can communicate is compounded by the vast increase in the number of communications taking place and the increase in the amount of information available on the Web. To avoid 'communication overload', it is vitally important to develop a strategy for dealing with information that is important while discarding anything irrelevant. Do not feel obliged to spend valuable time reading and responding to every email or web message.

\section{C) THE WEB AND THE PRACTICE OF DENTISTRY}

How do web resources, such as those highlighted in chapter 8 , translate into practical benefits in the dental setting?

\section{Efficient dissemination of information}

The Internet is now the prime method of disseminating information for many large organisations, such as the NHS and the Department of Health (DoH). There are enormous savings to be made in not having to publish and post paper-based information to large numbers of people.

For example, before and during the implementation of the nGDS contract, the DoH used the postal service to inform dentists of the latest developments, while at the same time informing them of the website addresses where they could then download more complete documentation. Another example is the National Institute for Clinical Excellence (NICE) guidelines on the recall interval for dental examinations. When these were first published, dentists were sent a brief printed summary. Within this summary was printed the hyperlink to the full 68 page document. ${ }^{14}$ In this way, people who wanted to read the full evidence, methods and findings could do so, but without the expense of having to print it out centrally and post it to tens of thousands of dentists. Within a short period of time, many dental websites carried a link to the NICE guidelines, thereby greatly increasing access to this document.

Although this form of circulating information can be very cost effective for the organisations involved, it does assume that every dentist has access to the Internet, knows how to navigate their way through some very large websites and is familiar with opening and saving pdf files.

\section{Access to databases}

As yet there are no online databases whose immediate access is essential for the practice of dentistry. However, if the practice has a broadband connection, then the electronic British national formulary (BNF) ${ }^{15}$ is well worth using. It is much faster navigating online than using the printed version, especially when looking up drug interactions or finding the correct spelling for a drug. The online version will always give you the most accurate and up-todate prescribing information. It is also useful to have access to the General Dental Council's database $^{16}$ of dentists, dental specialists, dental hygienists and dental therapists. This tool will become even more important now that the register has been extended to cover dental technicians and nurses.

\section{Keeping informed}

News travels fast and there are many occasions when patients ask their dentists about a dental news item that they have just read in the newspaper or heard on the radio. With the Internet it is easy to be just as informed as the patient, since the BBC and most newspapers have a significant online presence. The Smileon.com ${ }^{17}$ and BDA $^{18}$ websites are also both excellent sources for current dental news.

\section{Keeping one step ahead}

The British Dental Journal ${ }^{19}(B D J)$ has always been the first port of call for dentists looking for a new job, but it is only published fortnightly. On the other hand, the classified section of the electronic $B D J$ is updated daily and therefore is the best place to read the adverts first.

\section{Taking information on the move}

Personal digital assistants (PDA or electronic 'Filofax') have become popular in a number of hospitals, clinics and medical practices. An assortment of software has been produced for medical healthcare specialties to provide mobile access to clinical reference, patient information and data communication. A small number of downloadable programs have been written for the American dental market ${ }^{20}$ and their use in orthodontics has been considered in the UK. ${ }^{21}$ The latest PDAs come with built-in wireless connectivity and this has been shown to be of use in the clinical setting. Indeed, a pilot assessment ${ }^{22}$ by students at GKT Dental Institute showed that wireless 


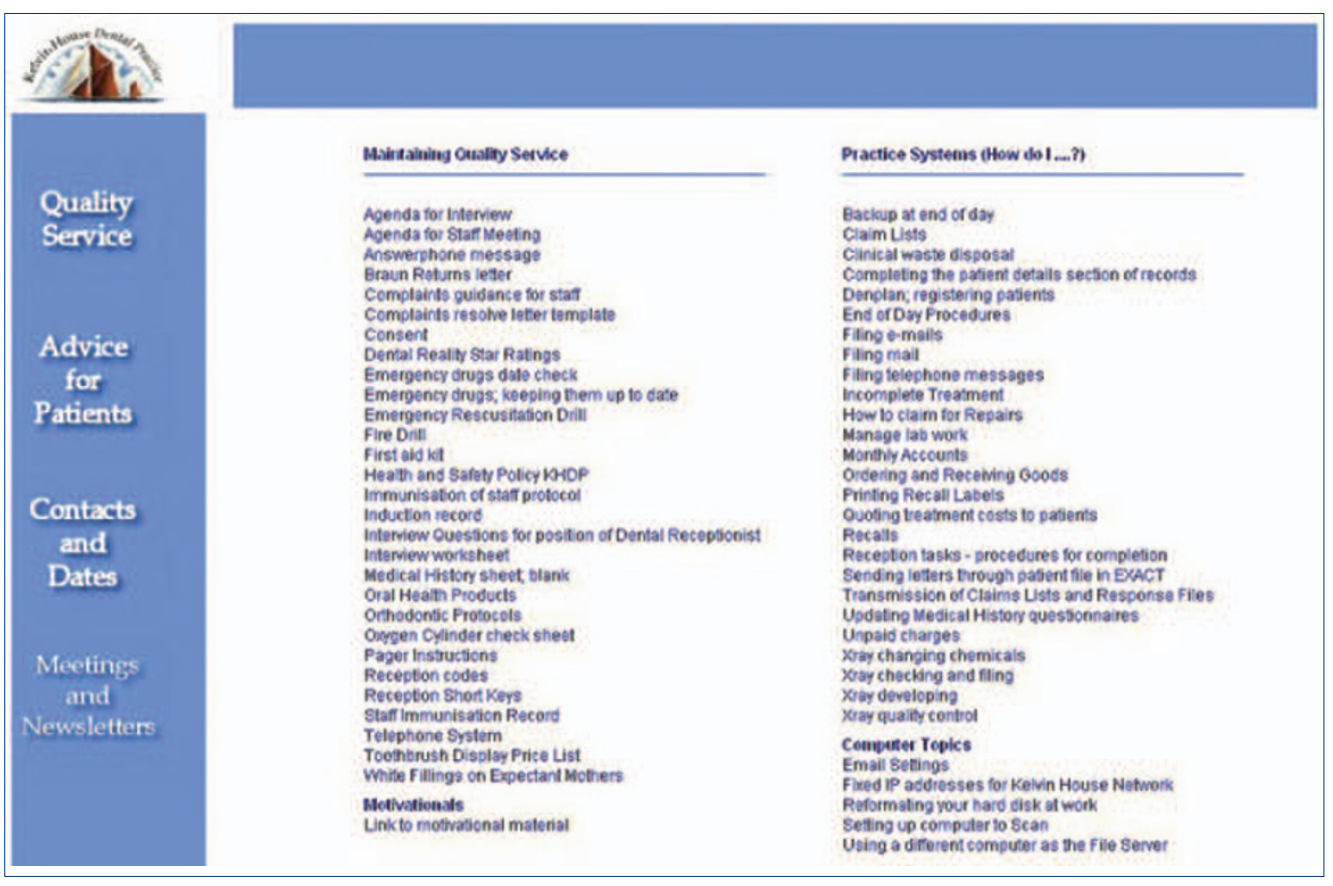

access by PDAs to college networks worked well and PDAs were highly acceptable as a means to access online education. There are plans to try and incorporate the use of PDAs for all GKT dental students throughout their five-year curriculum.

DentalMedSoft have produced an interactive textbook of oral pathology ${ }^{23}$ for use on a Palm PDA while the BNF is working on a PDA version of its formulary. The Oxford University Press has published their Oxford handbook of clinical medicine as a downloadable file for use on a PDA, along with seven other medical titles. Hopefully, it will not be too long before the excellent Oxford handbook of clinical dentistry will be available in the same format. The advantage of having a book on a PDA is that it is easily transportable, upgradeable and supports the use of bookmarks and notes.

One word of caution: carrying around patient information on any portable device (be it a PDA, tablet PC or laptop) brings up serious issues of security and data protection. Some new portable devices now include an integrated fingerprint reader.

\section{Digitising models and images}

There are many new CAD dental systems that utilise the Internet for passing data to and from the practice. One example is OrthoCAD Digital Models; ${ }^{24}$ the dentist sends in impressions for study models and later downloads via the Internet a set of virtual models. This saves valuable space normally required for archiving plaster models. The digital models can be found/viewed instantly and a set of software tools help with diagnosis and treatment planning. The company keeps copies of all digital models for 10 years, ensuring that data is backed up.

Smile-Vision ${ }^{25}$ offers an online cosmetic imaging service that enables the dentist and patient to view a digital mock-up of how their teeth may appear following cosmetic treatment.

Training in the use of materials

Training a member of staff on how to use a new material can be assisted by using animations or video from the manufacturer's website. The Free Tutorials section on the Dentrek $^{26}$ website has links to over 50 such tutorials from various dental companies. Most dental trade websites contain copies of instruction manuals for materials/equipment as well as copies of all the associated material safety data sheets.

Using HTML to produce simple custom applications

Not strictly on the web, but using web technology, it is possible to use the power of hyperlinks to create simple documents and groups of documents that can help to educate patients and manage the practice.

- PowerPoint or Word can be used to create interactive patient education software for use either in the waiting room or surgery. Making use of the hyperlink feature in both programs, it is easy to create clickable links to move from one part of the presentation to another. Such a document could also be copied onto a CD-ROM for patients to take away, or be downloadable from the practice website

- A simple web page template can be used to create and manage practice protocols, patient information leaflets, newsletters, contact details etc. The data can be stored on the practice file server so that every computer in the practice can access and share the information via Internet Explorer, without the need to be online (Fig. 2).
Fig. 2 This screen shot shows the first of four simple HTML pages with hyperlinks to hundreds of Word documents that make up a complete dental practice management system 
Downloading business software and data

In addition to dental resources, the web is an invaluable source of non-expensive/free software, files, databases and general information for use in business. The Internet can also enhance the software already running on a practice computer.

- Many medium/large businesses are now using voice over Internet protocol (VoIP) software such as $\mathrm{Skype}^{27}$ to make substantial savings on their telephone bills

- BT Directory Enquiries ${ }^{28}$ has an online tool that allows the user to make ten free personal/business directory enquiries per day. The results show the telephone number, address and link to a map

- Open source software such as OpenOffice ${ }^{29}$ provides a multi-platform office suite that includes applications such as a word processor, spreadsheet, presentation manager and a drawing program

- There are literally thousands of software programs that are only readily available via the web. These programs can increase the productivity and efficiency of any computerised practice and include task automation, remote access, file compression, project management, time management, loan calculators, templates for Word/Excel and utilities for making backups, labels, business cards, business plans and pdf files

- The Inland Revenue website ${ }^{30}$ is one of the most visited sites in the UK and contains a wealth of information to help manage taxation and national insurance. It is possible to file self-assessment tax returns and make tax payments online. They also provide a list of Internet-enabled payroll software programs that can be used to file PAYE forms and returns online to the Inland Revenue
- Most banks now provide an online banking service for both personal and business accounts. As well as being able to keep a closer eye on the state of finances, it is also a convenient way of transferring money between accounts and managing standing orders and direct debits

- There are many UK services, such as Egg Money Manager, ${ }^{31}$ which enable a person to see all of their online accounts in one place. This includes bank and building society accounts, credit cards, store cards, loan accounts and investments. With one click it is possible to go straight to the other banks' websites without any additional logging in procedure

- Personal/small business accounting software such as Microsoft Money have many Internet features such as being able to download data directly from a bank account, thereby increasing accuracy and speeding up data entry. Automatic stock and investment quotes can also be used to update any savings portfolio

- There is a wide range of websites that offer business advice. One example is Business Link, ${ }^{32}$ a site run by the Small Business Service, an executive agency of the UK Department of Trade and Industry. It offers practical advice for setting up and running a business.

\section{Dental software; an open source program}

Open Dental ${ }^{33}$ is an open source dental practice system that can be downloaded on a free trail basis (30 patient limit). Open source means that anyone is free to copy, distribute and change the software, as long as the copyright notice and license remains intact. The program has been copyrighted by Dr Lordan Sparks, to prevent anyone from turning it
Fig. 3 This screen shot shows a live web cast from smile-on.com. It illustrates some of the interactive features that enable participants to ask questions and provide feedback to the speaker

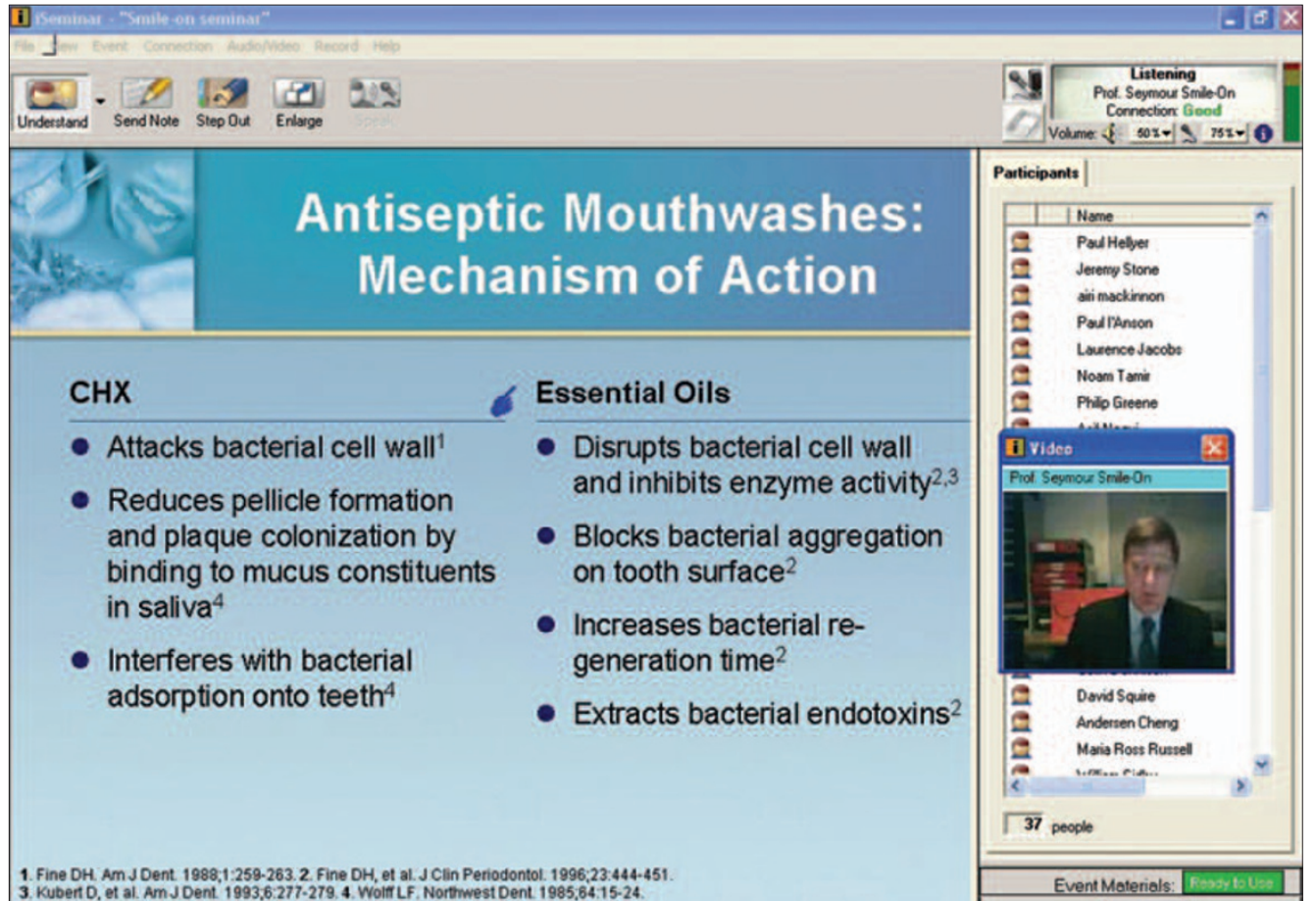


into a proprietary system. The cost for full telephone support in the first year is $\$ 139$ per month, going down to $\$ 99$ per month for subsequent years. The website includes a discussion forum for users of the software.

Many dentists use the Internet more at home than they do at work. Sometimes this is simply because it is more convenient to web browse from home, and sometimes it is because of a conscious decision not to have web access at work. Using the web can be time consuming and can be a distraction at work. The theory of having instant access to useful professional and business sites is sometimes replaced by the realty of burdensome passwords to gain access.

\section{D) CPD AND THE INTERNET}

Although I have left this topic to the end, it is just as important as the other three areas covered. Distance learning using computers has always had a warm reception in dentistry and it really started to develop in the UK in 1991 when the Department of Health funded the first of many computer assisted learning (CAL) programs. ${ }^{34}$ The Internet has simply expanded the horizons of what can be achieved by providing on-demand delivery of multimedia content, immediate access to vast libraries of research material and real-time interaction between instructors and learners. The term e-learning has been coined to reflect the increasing use of the Internet and multimedia in distance learning. As with any information from the Internet, it is important to critically evaluate the relevance and quality of any e-learning materials. ${ }^{35}$ It is also necessary to realise that web-based learning will not necessarily suit everyone. ${ }^{36}$

E-learning will never replace physically attending courses, but it can be flexible, interactive, give instant encouragement and feedback, be carried out at one's own pace and avoids having to be away from the practice. Here are some examples:

E-learning with a medium/high level of human interaction

- Web casting and web conferencing are two different web technologies that are beginning to converge. Web casting is a one-to many 'event', comparable to a TV broadcast, in which live or pre-recorded audiovisual material is sent from a central location out to viewers over the Internet. Web conferencing is more similar to a face-to-face meeting with various degrees of presentation, interaction and collaboration among multiple computer users. Smile-on.com ${ }^{17}$ held their first "virtual seminar' web cast in May 2004, when 50 participants watched a live presentation by Professor Robin Seymour, Dean of Newcastle Dental School (see Fig. 3). After the presentation, users could pose questions by either speaking into their computer's microphone or by typing their question. The Dental Channel Limited, ${ }^{37}$ started by dentist Andrew Gould, also provides live interactive lectures called 'webinars'. The webinars currently cover such topics as endodontics, restorative dentistry and practice management and supplement their award-winning series of CD-ROM CAL programs

- Online study groups. The Dental Practice-Based Research Network ${ }^{38}$ is based in the University of Alabama. It is an international consortium of participating practices and dental organisations that are committed to advancing knowledge of dental practice and ways to improve its effectiveness. The website consists of an online study group and an area for research training. It aims to enable dentists to conduct research about and in the 'real world' of dental practice. In April 2005 it received a \$25 million grant to fund its objectives

- Online learning combined with group meetings is becoming popular. The Eastman Dental Institute has developed a range of distance learning opportunities ${ }^{39}$ for dentists, some of which combine downloading information from the Internet, working with the material either individually or in small groups and later meeting up for a joint clinical day. The GKT Dental Institute offers an M.Clin.Dent. (Prosthodontics) ${ }^{40}$ where students are supported online via a virtual learning environment and through intensive residential courses

- Teledentistry is a combination of telecommunications (including the use of the Internet) and dentistry; it involves the exchange of clinical information and images over remote distances. Dental-Consults $^{41}$ is a website set up by Dr Vinod K. Joshi, a consultant in restorative dentistry. The site provides fee-based teledentistry consultation services covering most dental specialties. The system enables referring dentists to upload information about a patient, including dental images and radiographs, for a specialist second opinion. Advantages over a more traditional private referral include:

- Saving patients the time and cost of travel

- One hour of verifiable CPD for each referral

- A diagnosis and treatment plan provided within five working days after receipt of the complete patient case.

- Dental forums have been created to cover particular clinical topics. For example, the Invisalign $\mathrm{n}^{42}$ orthodontic appliance system not only has an 'online clinical education center' to help practitioners master the technique but also provides an extra element of human interaction by hosting a community forum and an area for users to submit cases and tips. Another example is 
Fig. 4 The University of Birmingham School of Dentistry's Ecourse for undergraduates is just one of its many online resources

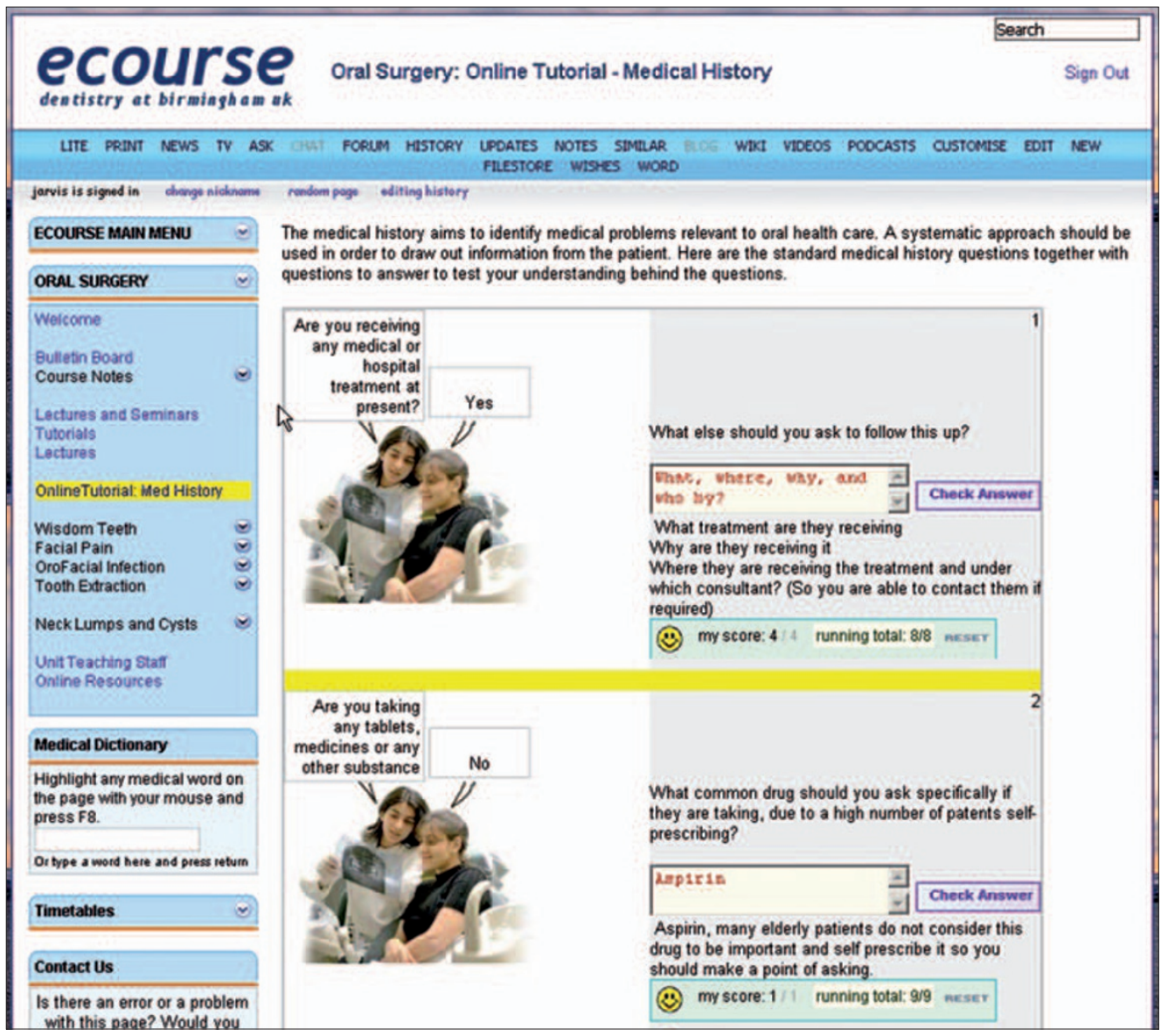

the Dentaltown ${ }^{11}$ website, which has many interesting features that encourage dentists to participate in the learning process. Each 'feature' article has an option for the reader to leave a comment that can then be seen by other readers. There is a regular poll about a particular dental issue, the results of which are then well presented in a summary page. In the Clinical Cases section, members put up digital images of interesting cases they are treating, with a view to requesting ideas and comments from other members. There is an active message board section with discussions taking place in over 100 different topic categories.

\section{E-learning with a medium/high level of computer interaction}

- Undergraduate online courses are available from many dental websites with varying degrees of computer interaction. Many dental schools have now developed online educational resources for their undergraduate students. Most of these lie behind password-protected sites and are therefore not publicly accessible. However, the University of Birmingham School of Dentistry website does show samples of its Ecourse $^{43}$ undergraduate pages (Fig. 4). One major advantage for undergraduate students studying online is that hyperlinks bring together diverse but related topics, allowing better integration of the different dental disciplines
- Online courses for the dental team are becoming more available. Birmingham School of Dentistry has set up CPD-HQ, ${ }^{44}$ which aims to deliver verifiable CPD to all dentists via the Internet 'with emphasis on interactivity and self-assessment'. There are currently ten learning modules available and the cost for a year's subscription is £199. Smile- $0 n^{17}$ has about ten online courses, ranging from 0.5 to 1.5 hours of $\mathrm{CE}$, covering restorative topics, clinical governance and clinical audit. In conjunction with the Faculty of General Dental Practice (UK), Smile-On has also introduced Key Skills in Primary Dental Care. This package, which is aimed at all members of the dental team, is available either online or on CD-ROMs (which cost an additional £20). The website also keeps a record of all finished courses and enables users to print certificates of completion. It can also be used to keep a note of other CPD activity, such as reading journals, attending lectures or presenting papers at conferences. Such a log can be of great help when it comes to compiling an annual CPD declaration for the GDC. The Eastman Dental Institute ${ }^{45}$ and the Birmingham School of Dentistry ${ }^{46}$ websites host some small CAL programs, some of which have an interactive quiz with scoring. As the GDC now requires dentists to carry out verifiable CPD in three core recommended subjects, interactive e-learning courses 
such as the Eastman's CPD radiography course for the dental team will come into their own. Expecting specialist speakers to spend a large amount of their time lecturing all over the UK on a repetitive subject matter always seemed to be a poor use of scarce resources. The BDA's ${ }^{18}$ online course, leading to an NEBDN Certificate in dental radiography for dental nurses, enrolled over 300 nurses in 2006; there was an $89 \%$ first time pass rate

- Notification of articles and new web content is one way of using the Internet to keep up-to-date with newly published information in any particular field. Many electronic magazines and journals send an email alert to notify users when new content goes online. This is often a free service with no requirement to subscribe to the magazine or journal. Some journals will alert you whenever new content is published that matches criteria based on the topics, authors and articles you want to track. There is also an increasing use of RSS feeds (really simple syndication) as another way to receive automatic updates from your chosen websites. Instead of having to go out and find the information, these features makes it possible to have upto-date information that you are interested in, sent to you automatically.

\section{E-learning with minimal computer/human interaction}

This category of e-learning covers the rest of self-directed and self-paced learning.

- Online versions of printed dental journals are now the norm and benefit from the ease of searching; full access to such online journals is mainly reserved for paying members although there are a number of journals that do not require subscription (listed in chapter 8). Many journal websites, including the $B D J$, use advance online publication (AOP) to get articles to their readers even before they appear in print

- Online-only dental journals, such as the Journal of Contemporary Dental Practice ${ }^{47}$ are only ever published online. Being an online journal, it does not have the limitations of printed journals and can use animations, video clips and short audio recordings to enhance the learning experience. Other online journals, such as BioMed Central Oral Health ${ }^{48}$ have the advantage of being able to publish peerreviewed articles within a few weeks of acceptance, as opposed to the many months that traditional printed journals require. As an electronic-only journal, they also have the flexibility of being able to publish large datasets and large numbers of illustrations; they can also display data in a form that can be read directly by other software programs
- Online self-assessment has been linked to peer-reviewed journals. The British Dental Journal, ${ }^{19}$ in conjunction with Eastman Continuing Professional Development, offer an online verifiable CPD service whereby you answer questions related to peer-reviewed articles published in the British Dental Journal. This service is free to members of the BDA and costs $£ 10$ for non-members. There are two chosen articles per issue of the journal, with each article answered earning one hour of verifiable CPD. There are currently over 3,000 dentists accessing the site every month to submit answers online. There is a similar scheme in place with the Faculty of General Dental Practice (UK), ${ }^{49}$ whereby members can complete a quarterly online quiz, linked to their journal Primary Dental Care. Answers are marked electronically and the results emailed back within an hour. Each quiz counts as three hours of verifiable CPD. Dental Update ${ }^{50}$ also offers members online CPD in partnership with Colgate. Answering multiple choice questions from each issue is rewarded with up to four hours of verifiable CPD per month. Its website also keeps a record of any articles that you have accessed online and labels them as part of your unverified CPD. In 2006, over 50,000 articles were read online on the Dental Update website

- Podcasting has started to become a popular method for distributing dental information by sound and video. The DentalCast ${ }^{51}$ website is a network of dentally related podcasts with over 30 podcasts available for download; the site receives over 5,000 downloads per month

- For accurate and concise information on a particular dental topic, dental society/ association guidelines are a good place to start. They are aimed at improving the effectiveness and efficiency of clinical care through the identification of 'best' clinical practice. The guidelines can assist the dental team in making decisions about the most appropriate treatment and can form part of a practice policy. The Internet is the ideal place to store and access such articles, as they can easily be kept up-to-date and are an inexpensive way of disseminating information. Dental trade companies often put useful resources on their websites, for example the series of online lectures on how to achieve aesthetic composite restorations from Cosmedent. ${ }^{52}$ The companies benefit from enabling the immediate purchase of materials and equipment mentioned in the lectures, and dentists benefit from access to free information that they can readily put into clinical practice

- Online library resources have blossomed in the NHS as part of a new electronic knowledge service to support healthcare. 
Fig. 5 Netskills offers a training and staff development service to help the UK higher education community make effective use of the Internet. The free online TONIC course contains over $\mathbf{4 0}$ hours of learning material

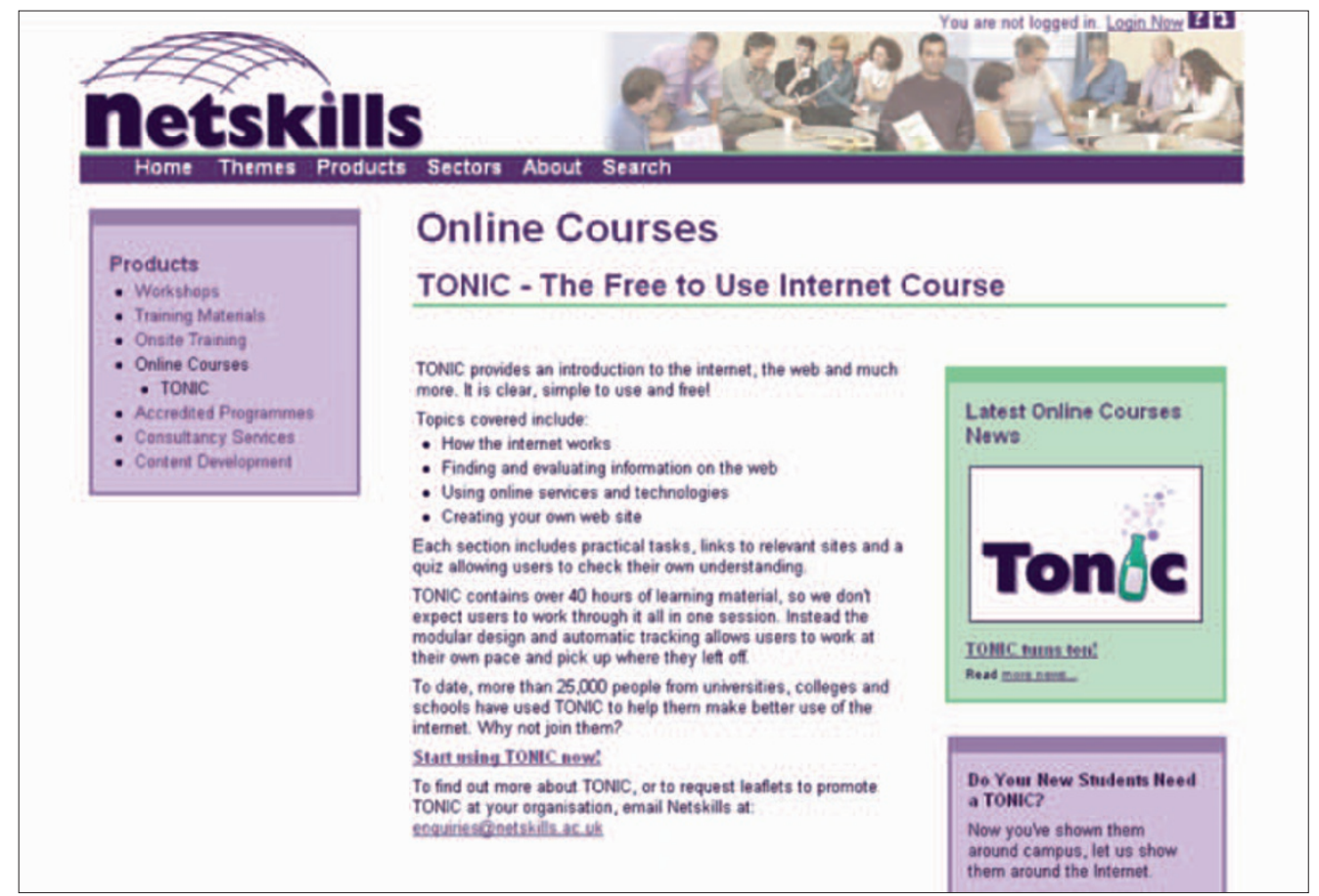

Examples include the National Library for Health, ${ }^{53}$ Health on the Net Northern Ireland, ${ }^{54}$ E-library NHS Scotland ${ }^{55}$ and the Health of Wales Information Service. ${ }^{56}$ Each library acts as a portal to specialist libraries, guidance, evidence, clinical databases, journals, books and online resources for patients. An Athens account ${ }^{57}$ is necessary to access these libraries and is available to any dentist working in the NHS. Using an Athens ID it is possible to create search profiles of single or multiple databases and save them for future use. Although the specific dental content linked to these sites is relatively small, the Athens subscription does enable free access to some other sites that may interest dentists, such as anatomy.tv $v^{58}$ and images. md. ${ }^{59}$ Many dentists use the PubMed ${ }^{60}$ website to research a particular dental topic. Unfortunately, the vast majority of results normally only show an abstract of the paper with a link to the publishing journal. If you do not have a paid subscription to that particular journal, it can cost \$10-\$20 to obtain a download of the article. However, results that have links to free full text articles are becoming more common. Chapter 8 lists a large number of other research tools available online.

The Internet as an adjunct to conventional lectures and hands-on courses

The Internet can be extremely useful as an adjunct to conventional postgraduate courses. It can be used for finding an appropriate course in the first place, booking onto the course, finding the location of the venue and booking transport/accommodation (laterooms.com ${ }^{61}$ can save you money on hotel accommodation, especially at weekends).
The Internet can also be utilised to discover background information about the speaker(s), to communicate with the speaker before/after the event and for following up online references after the course.

Some courses have web-based multimedia content to supplement hands-on lectures. For example, the postgraduate lecture on back care from GKT recommends the Back Care for the Dental Student website, ${ }^{62}$ so that participants can review the advised exercises by playing the video clips.

In the future it may become commonplace for conferences to provide delegates with access to a password-protected website that holds the PowerPoint presentations or video of the lectures and also includes a forum for questions and answers. Delegates and speakers could then use this forum for a set period of time after the event as part of their learning 'experience'. The 2003 Dental Informatics and Dental Research Conference ${ }^{63}$ is an example of how a conference can be archived onto the web. The archival site contains the conference program, all presentation abstracts and presentations (either as PowerPoint or pdf files), links to the full conference papers, the attendee list, sponsor links and photographs of the conference. The Dentalk ${ }^{64}$ website from Australian dental lecturer Geoff Knight and the PerioCourses ${ }^{65}$ website from the UK's Graham Smart and Philip Ower are both examples of how course material from previous seminars can be password-protected for later use by participants of the course.

Training the dental team in using the Internet It goes without saying that it is essential to train every member of the team who is going to use the Internet. It is probably best to start with a hands-on course, followed up by 
reading, practice and online tuition. Postgraduate deaneries normally have details of local IT training; this is often in the form of hands-on sessions plus online tutorials via LearnDirect. Usually this training is free for all staff members working in the NHS. Other resources for learning more about using the Internet are the Webwise site from the $\mathrm{BBC}^{66}$ and the free Tonic ${ }^{67}$ online course from Newcastle University (Fig. 5).

\section{CONCLUSION}

The hardware, software and means of Internet connection are now well established and are continuing to evolve at break-neck speed. However, the dental team's uptake of this technology has not kept pace with its development. This may be due to ignorance about the advantages of the Internet or simply because of a lack of suitable training.

There are still many problems with the Internet that need to be 'ironed out' to make the process of using it more user-friendly, safer and more productive. Difficulty in accessing reliable information, concerns over security, 'information overload', copyright issues and just the sheer pace of new technological developments are unlikely to ever go away, but hopefully they will become less of an inconvenience.

It is still possible to run a busy dental practice successfully without the Internet, but only just; this will become progressively more difficult. Having access to email and to the web is becoming increasingly necessary as organisations and companies rely on the Internet as a cheap and easy way of communicating. Those dentists who have fully embraced the Internet are already reaping the benefit of having access to the biggest 24-hour library and resource centre in the world. They have found that the Internet has significantly transformed part of their working life.

1. Schleyer T K, Spallek H, Bartling W C, Corby P. The technologically well-equipped dental office. J Am Dent Assoc 2003; 134: 30-41.

2. Filippini and Gray crown and bridge specialists. http://www.filippini-gray.com/

3. Dental Practitioners Association website http://www.uk-dentistry.org/

4. Chestnutt I G, Reynolds K. Perceptions of how the Internet has impacted on dentistry. Br Dent J 2006; 200: 161-165.

5. ArchWired blogger website. http://www.archwired. com/phpbb2/index.php

6. The Dental Directory. http://www.dental-directory.co.uk/

7. Schottlander. http://www.schottlander.com/

8. Net32.com dental supply comparison shopping. http://www.net32.com

9. Schleyer T, Spallek H, Spallek G. Computing in dentistry. http://www.dental-computing.com/public/ book-concept.html

10. Proffit W R, Fields H W, Sarver D M. Contemporary orthodontics e-dition. $4^{\text {th }}$ ed. UK: Elsevier, 2007.

11. Dentaltown. http://www.docere.com/Dentaltown/ SiteDefault.aspx

12. GDP-UK mailing list. http://health.groups.yahoo.com/ group/GDP-UK/

13. Internet helps dentists organise protest. Br Dent J 2005 199: 637.

14. National Institute for Health and Clinical Excellence. Dental recall - recall interval between routine dental examinations. London: NICE, 2004. http://www.nice.org. uk/page. aspx $? 0=225866$

15. British National Formulary website. http://bnf.org/

16. General Dental Council website. http://www.gdc-uk.org/

17. Smile-on website. http://www.smile-on.com/

18. British Dental Association website education page. http://www.bda.org/education/index.cfm

19. British Dental Journal website. http://www.nature.com/ bdj/index.html

20. Palm PDA software. http://palmsource.palmgear.com/

21. Hirani S, Hodgkins J, Chen S D M, Lucas G. Personal digital assistants in orthodontics. Br J Orthod 2005; 32: 61-68.

22. Reynolds P A, Harper J, Dunne S, Cox M, Myint Y K. Portable digital assistants (PDAs) in dentistry: part II - pilot study of PDA use in the dental clinic. Br Dent J 2007; 202: 477-483.

23. DentalMedSoft PDA textbook.

http://www.dentalmedsoft.com/

24. OrthoCAD Digital Models. http://www.orthocad.com/ services/Study_Models.htm

25. Smile-Vision website. http://www.smile-vision.net/

26. Dentrek free tutorials. http://www.dentrek.com/

27. Skype website. http://www.skype.com/

28. BT Directory Enquiries website. http://www.thephonebook.bt.com/

29. OpenOffice. http://www.openoffice.org/

30. HM Revenue and Customs website. http://www.hmrc.gov.uk/

31. Egg Money Manager. http://money-manager.egg-online.co.uk/

32. Business Link website. http://www.businesslink.gov.uk/

33. Open Dental. http://www.open-dent.com/

34. Eaton K. CAL for dentists - where have we been? Where are we going? http://www.eastman.ucl.ac.uk/cal/bscd99/ 04 eaton/index.html

35. Eaton K A, Hammick M. Distance learning materials for dentists - a users guide to quality. Br Dent J 2003; 194: 253-256.

36. Holt RD, Oliver M. Evaluating web-based learning modules during an MSc programme in dental public health: a case study. Br Dent J 2002; 193: 283-286.

37. The Dental Channel Limited. http://www.dentalchannel.co.uk/

38. Dental Practice-Based Research Network. http://www.dentalpbrn.org/

39. Eastman Continuing Professional Development website. http://www.eastman.ucl.ac.uk/cpd/

40. GKT Dental Institute M.Clin.Dent. (Prosthodontics) course. http://www.mscdentistry.org/Clinical_Dent_ introduction.htm

41. Dental-Consults. http://www.dental-consults.com/ index.html

42. Invisalign online clinical education center. http://www. invisaligncec.com/ [requires registration to access].

43. Birmingham School of Dentistry Undergraduate Ecourse. http://www.dentistry.bham.ac.uk/ecourse/home/

44. Birmingham School of Dentistry CPD-HO. http://www.cpd-hq.com/

45. Eastman CAL programs. http://www.eastman.ucl.ac.uk/ education/ednl_resources/cal/index.html

46. Birmingham School of Dentistry CAL online and downloads. http://www.dentistry.bham.ac.uk/ecourse/cal/ welcome.asp

47. Journal of Contemporary Dental Practice. http://www.thejcdp.com/index.htm

48. BioMed Central Oral Health. http://www.biomedcentral. com/bmcoralhealth/

49. Faculty of General Dental Practice (UK) website. http://www.fgdp.org.uk/

50. Dental Update website. http://www.dental-update.co.uk/

51. DentalCast. http://www.dentalcast.net/

52. Cosmedent. http://www.cosmedent.com/index.asp

53. The National Library for Health. http://www.library.nhs.uk/

54. Health on the Net Northern Ireland. http://www.honni. qub.ac.uk/

55. E-library NHS Scotland. http://www.elib.scot.nhs.uk/

56. Health of Wales Information Service. http://www.wales. nhs.uk/

57. Athens account registration. https://register.athensams. net/nhs/

58. PubMed. http://www.ncbi.nlm.nih.gov/entrez/

59. Anatomy.tv. http://www.anatomy.tv/

60. Images.md. http://images.md/

61. Laterooms.com. http://www.laterooms.com/

62. GKT back care for dental students. http://www.kcl.ac.uk/ teares/gktvc/vc/It/dentalex/about.html 
63. Dental Informatics and Dental Research Conference archive. http://www.dentalinformatics.com/conference/ index.html

64. Knight G. Dentalk. http://www.dentalk.com.au/ seminar-notes.html
65. PerioCourses. http://www.periocourses.co.uk/login.shtml 66. BBC Webwise.

http://www.bbc.co.uk/webwise/index.shtml

67. Tonic online course. http://www.netskills.ac.uk/content/ products/online/

\section{IF (YOU COULD BE A TRAINER)}

If you can keep your head when all about you moan are losing teeth and blaming it on you.

If you can trust yourself when patients groan but make allowance for their plight and droning too.

If you wait, but can relate to no-shows or being lied about don't fall apart, or being feared, deal with their woes, yet never look too glum or act too smart

If you can ride each political wave and whim or better still predict the forthcoming craze.

If you can talk with advisers and keep up your chin Keep up with progress - nor lose the IT ways.

If you can bear to hear the truth you've spoken twisted by youth to make a trap when old,

or watch the teeth you gave your time to broken restored again with cusps and fissures bold.

If neither GDC or PCT can hurt you.

You walk with deans nor lose the common touch.

If either National Health or Private - you treat with virtue and all patients count with you, but none too much.

If you can fill the worthwhile hour with sixty minutes of know-how taught.

Keep all your knowledge fresh not sour with open mind and all best practice sought.

If you can make any sense of all your tutorials and risk losing face to show and share, and next year start again at VDP beginnings, and never breathe a word how much you care. If you can force your heart and nerve and sinew to serve your colleague long after they are gone, and so hold on when there is nothing in you, except the will which says to them well done

If you can lean there and back and not hurt your back. Glean UDAs, but not make them your aim.

If you meet with very busy and slack and treat those two imposters just the same.

If you can keep your practice in balance and yet maintain a happy caring team. you are a worthy trainer and gallant and what is more a worthy training scheme.

...with apologies to Rudyard Kipling

\section{T. Noel Davies}

VDP Trainer 